\title{
Incidence and Determinants of Reported Hypoglycaemia among Patients with Type 2 Diabetes Mellitus in a Tertiary Health Institution in Nigeria
}

\author{
Michael Adyemi Olamoyegun'1, Ala Oluwabukola Ayodele², Enikuomehin Adenike Christianah³, \\ Akinlade Taofiq Akinyele ${ }^{4}$ \\ ${ }^{1}$ Department of Internal Medicine, Endocrinology, Diabetes \& Metabolism Unit, Ladoke Akintola University of \\ Technology/LAUTECH Teaching Hospital, Ogbomoso, Oyo State, Nigeria \\ ${ }^{2}$ Department of Medicine, Bowen University/Bowen University Teaching Hospital, Ogbomoso, Oyo State, Nigeria \\ ${ }^{3}$ Department of Medicine, University of Medical Sciences/University of Medical Sciences Teaching Hospital, Ondo, Ondo State, Nigeria \\ ${ }^{4}$ Department of Medicine, General Hospital, Odan, Lagos Island, Lagos State, Nigeria \\ Email: maolamoyegun@lautech.edu.ng
}

How to cite this paper: Olamoyegun, M.A., Ayodele, A.O., Christianah, E.A. and Akinyele, A.T. (2020) Incidence and Determinants of Reported Hypoglycaemia among Patients with Type 2 Diabetes Mellitus in a Tertiary Health Institution in Nigeria. Journal of Diabetes Mellitus, 10, 51-63. https://doi.org/10.4236/jdm.2020.102005

Received: February 27, 2020

Accepted: May 5, 2020

Published: May 8, 2020

Copyright $\odot 2020$ by author(s) and Scientific Research Publishing Inc. This work is licensed under the Creative Commons Attribution-NonCommercial International License (CC BY-NC 4.0). http://creativecommons.org/licenses/by-nc/4.0/ (c) (i) (s) Open Access

\begin{abstract}
Introduction: Hypoglycaemia is a frequent and serious adverse effect of anti-diabetic therapy associated with both immediate and delayed adverse clinical outcomes. However, it continues to be a neglected complication with limited study of its burden, knowledge, determinants and preventive measures adopted by type 2 diabetics. Methods: Patients with type 2 diabetes who presented at Diabetes Clinic of a University teaching hospital and fulfilled selection criteria were recruited. The information obtained included sociodemographic, clinical details with hypoglycaemic symptoms and laboratory measurements. Results: There were 113 participants with a mean age of $60.94 \pm$ 11.95 years. The majority of the patients had fair knowledge of hypoglycaemic symptoms and also knew what actions to take to ameliorate the symptoms when it occurs. The incidence of hypoglycaemia was $45.1 \%$ and most commonly occurred in the afternoon before lunch. The commonest symptoms reported by patients were shivering $(76.1 \%)$, hunger $(71.7 \%)$ sweatiness (71.5\%) and weakness (69.9\%). Almost one-fifth (19.6\%) of those who reported hypoglycaemia had severe symptoms, of which $16.1 \%$ had hospital admission for its management. Use of insulin, duration of diabetes, age and possession of glucometers were some of the determinants of hypoglycaemic symptoms. Conclusions: The burden of reported hypoglycaemia among type 2 diabetics is significant. Hence, diabetics at risk should always be asked about symptoms at each clinic visit. Early recognition of hypoglycaemia risks,
\end{abstract}


self-monitoring of blood glucose (SMBG), appropriate education programs for both health care providers and patients with diabetes are the major ways to minimize risks of hypoglycaemia.

\section{Keywords}

Diabetes Mellitus, Epidemiology, Hypoglycaemia, Knowledge, Predictors, Risk Factors

\section{Introduction}

Diabetes mellitus (DM) is a chronic disease that requires continuous medical care and patients' management education to prevent acute complication and reduce the risk of long-term complications [1]. Hypoglycaemia is an important complication in the treatment of type 2 diabetes mellitus (T2DM), because it causes morbidity, and is sometime fatal [2]. Achieving target glycaemic goals while avoiding hypoglycaemia is a major challenge in the management of patients with T2DM [3]. Hypoglycaemia is the limiting factor in the management of the vast majority of people with diabetes [4] [5].

Although landmarks studies like Diabetes Complications Control Trial (DCCT) and United Kingdom Prospective Diabetes Studies (UKPDS), demonstrated the benefits of intensive glycaemic control in type 1 and type 2 diabetes respectively [6] [7], the associated increased frequency of hypoglycaemia has limited the clinical implementation of such intensive therapy because of pharmacokinetics imperfection of available medications [7] [8] [9].

Hypoglycaemia is a medical emergency which requires prompt recognition, and treatment to prevent organ damage, especially the brain. Severe untreated hypoglycaemia can cause a significant economic and personal burden; therefore, identification and prevention can reduce diabetes burden by the prevention of hypoglycaemic complication. The UK Hypoglycaemia Study showed that in patients with type 2 diabetes, the risk of severe hypoglycaemia is low in the first few years (7\%) and that increases to $25 \%$ later in the course of diabetes [10]. However, the prevalence of T2DM is about 20 -fold higher than that of type 1 diabetes, and many patients with T2DM finally requiring treatment with insulin. Hence, most episodes of hypoglycaemia occur in patients with T2DM [11].

Hypoglycaemia is a common and serious complication of diabetes treatment especially in patients who do not have knowledge of the condition and personal glucose meters. It is the rate limiting complication in the achievement of strict glycemic control in diabetes management. Significant episodes of hypoglycemia and its attendant counter-regulatory hormonal response lead to poor glycemic control. The former may also be associated with cardiovascular and cerebrovascular morbidities [12]. Large trials (Action to Control Cardiovascular Risk in Diabetes (ACCORD), Veterans Affairs Diabetes Trial (VADT)) have shown that 
there was a higher mortality in the group that had hypoglycemia (intensively treated arm) [13] [14]. Hence, the American Diabetes Association (ADA) guidelines emphasize on individualizing targets and reducing risk of hypoglycemia in patients with long duration of diabetes and comorbidities [15].

The symptoms of hypoglycemia are varied. The symptoms may be nonspecific with intensity decreasing with increasing age. Thus, it is very important that the subjects are able to recognize and identify the symptoms onset at an early stage in order to manage the episode effectively and take steps to prevent the recurrence.

Patients with very good drug compliance are at greater risk of developing hypoglycaemia. Sometimes hypoglycaemia among patients on antidiabetic agents could be symptomatic or asymptomatic [16].

Although hypoglycaemia is a common complication among treated type $2 \mathrm{di}$ abetic patients, especially those on insulin either alone or in combination with oral anti-diabetic agents mostly the insulin sensitizers like sulphonylureas, there is little information about the burden and risk factors among Nigerians with type 2 diabetes. Hence, this study was aimed at assessing the knowledge of hypoglycaemic symptoms, burdens and predictors of hypoglycaemia among type 2 diabetics.

\section{Materials and Methods}

This study was done among type 2 diabetes mellitus patients attending the Diabetes Clinic of the Endocrinology, Diabetes and Metabolism Unit of LAUTECH Teaching Hospital, Ogbomoso.

Patients with T2DM whose diagnosis was made at the age of 30 years or older, and were on treatment with either oral anti-diabetic agents or insulin, or both, were recruited as a convenient sample size over a period of 6 months (January June 2017). Patients with Type 2 diabetes who were not on medications or those with Type 1 diabetes or pregnant women were excluded. Also excluded were those with T2DM complicated by major organ dysfunctions like heart failure, renal failure or liver dysfunctions. Information obtained from each of the patients included age, gender, educational status, duration of diabetes, and types of anti-diabetic agents used. Information obtained regarding hypoglycaemic symptoms included knowledge of hypoglycaemia, previous experience of hypoglycemia, methods of managing hypoglycaemia and possession of glucometers and frequency of self-monitoring of blood glucose (SMBG). Patients were asked if they have had any of the common symptoms suggestive of hypoglycemia in the past 6 months. The symptoms suggestive of hypoglycemia asked included, sweating, shivering (tremors), hunger, weakness, palpitation, headache, light headedness, anxiety, dizziness, blurred vision, and/or disturbance of consciousness, among others. Since most of the patients did not possess a glucometer to measure plasma glucose concentration especially during the occurrence of above or similar symptoms, they were asked if they ate something immediately 
following those symptoms and whether they were relieved of the symptoms. Also, all clinical suspicions of hypoglycemia were considered as occurrence of hypoglycemia especially if there were constellation of symptoms, even if unconfirmed with either laboratory blood glucose test or SMBG. Physical and biochemical measurements like weight, height, and average fasting plasma glucose were checked in each of the patients.

The study was approved by the Institutional Ethics Committee of the hospital (LTH/OGB/EC/2018/031) and each participant gave informed consent.

\section{Data Analysis}

Data were analysed using Statistical Package for Social Sciences version 21.0 software (SPSS Inc, Chicago, IL, USA). Continuous variables were presented as means \pm standard deviation while categorical variables were presented as frequencies and percentages. The factors associated with occurrence of reported hypoglycaemia were identified and test for association. All the factors that showed a significant association with the risk of developing hypoglycaemia on bivariate analysis were put into a multiple logistical regression model. Risk of developing hypoglycaemia was considered to be the outcome variable and the variables showing significant association as co-variants. The odds ratios and the $95 \%$ confidence intervals $(\mathrm{CI})$ were calculated. A p value $<0.05$ was considered as significant for all analysis.

\section{Definition of Operational Terms}

For the purposes of the analysis,

Mild hypoglycaemia: defined as patient report of typical symptoms of hypoglycaemia (eg, sweating, tremulousness, hunger, and/or dizziness) that were relieved by eating, or patient report of home glucose monitoring values of less than $60 \mathrm{mg} / \mathrm{dl}(<3.3 \mathrm{mmol} / \mathrm{L})$.

Severe hypoglycaemia: defined as loss of consciousness or other major alteration of mental status caused by hypoglycaemia that required the assistance of another person to manage the condition.

Asymptomatic hypoglycaemia: defined as low blood glucose values $<60 \mathrm{mg} / \mathrm{dl}$ ( $3.3 \mathrm{mmol} / \mathrm{L}$ ) but with no symptoms.

\section{Results}

Of the 113 participants, about $59.3 \%$ were females and the mean age of study participants was $60.94 \pm 11.95$ years. More than half of the participants had at least secondary school education. The prevalent occupation of the participants was trading (34.5\%) and civil service (32.7\%). Majority of the participants make less than N20,000 per month (56 USD, at 1 USD to N360). Sixty eight (60.2\%) were on oral anti-diabetic drugs only while $15(13.3 \%)$ were on insulin alone. The other distribution concerning sociodemographic and other indices are as shown in Table 1. 
Table 1. Sociodemographic characteristics and clinical data of the study participants $(\mathrm{n}=$ 113).

\begin{tabular}{|c|c|c|}
\hline Variable & Frequency & Percentage \\
\hline \multicolumn{3}{|l|}{ Sex } \\
\hline Male & 46 & 40.7 \\
\hline Female & 67 & 59.3 \\
\hline \multicolumn{3}{|l|}{ Education } \\
\hline None & 19 & 16.8 \\
\hline Primary & 35 & 31.0 \\
\hline Secondary & 11 & 9.7 \\
\hline Tertiary & 48 & 42.5 \\
\hline \multicolumn{3}{|l|}{ Occupation } \\
\hline Farmer & 14 & 12.4 \\
\hline Trader & 39 & 34.5 \\
\hline Artisan & 9 & 8.0 \\
\hline Professional & 6 & 5.3 \\
\hline Civil Servant & 37 & 32.7 \\
\hline Others & 8 & 7.1 \\
\hline \multicolumn{3}{|l|}{ Monthly Income ( } \\
\hline$<10,000$ & 48 & 42.5 \\
\hline $10,000-20,000$ & 22 & 19.5 \\
\hline $20,000-50,000$ & 12 & 10.6 \\
\hline $50,000-100,000$ & 20 & 17.7 \\
\hline$>100,000$ & 11 & 9.7 \\
\hline \multicolumn{3}{|l|}{ History of Hypertension } \\
\hline Yes & 84 & 74.3 \\
\hline No & 29 & 25.7 \\
\hline \multicolumn{3}{|l|}{ Diabetes Treatment } \\
\hline Diet alone & 1 & 0.9 \\
\hline OAD & 68 & 60.2 \\
\hline OAD + Insulin & 29 & 25.6 \\
\hline Insulin alone & 15 & 13.3 \\
\hline \multicolumn{3}{|l|}{ If $\mathrm{OAD}$} \\
\hline Metformin & 28 & 24.8 \\
\hline Metformin + SUs & 49 & 43.4 \\
\hline Metformin + SUs + Pioglitazone & 1 & 0.9 \\
\hline Metformin + DPP4-inhibitor & 1 & 0.9 \\
\hline Metformin + Pioglitazone & 1 & 0.9 \\
\hline SUs & 2 & 1.8 \\
\hline DPP4-inhibitor & 2 & 1.8 \\
\hline Age (Mean \pm SD) Years & \multicolumn{2}{|c|}{$60.94 \pm 11.95$} \\
\hline $\mathrm{BMI}($ Mean $\pm \mathrm{SD}) \mathrm{Kg} / \mathrm{m}^{2}$ & \multicolumn{2}{|c|}{$29.07 \pm 11.23$} \\
\hline FPG $($ Mean $\pm S D) \mathrm{mmol} / \mathrm{L}$ & \multicolumn{2}{|c|}{$9.05 \pm 3.48$} \\
\hline
\end{tabular}

OHA $=$ Oral Hypoglycaemic Agent, $\mathrm{SU}=$ Sulfonylurea, DPP4 $=$ Dipeptidyl Peptidase, BMI $=$ Body Mass Index, FPG = Fasting Plasma Glucose.

Regarding knowledge of hypoglycaemia, 95.2\% had good knowledge of hypoglycaemia as they were able to identify or recognize hypoglycaemic symptoms. Less than half of the participants, 56 (45.1\%) had experienced hypoglycemia in 
the last 3 months. The incidences of hypoglycaemic symptoms reported by the participants are as shown in Figure 1.

The commonest symptoms identified to be symptoms of hypoglycaemia were shivering (76.1\%), sweatiness (73.7\%), hunger (71.7\%) and weakness (69.9\%). Less study participants knew that aggression (32.7\%), convulsion (37.2\%) and anxiety (38.1\%) could be symptoms of hypoglycaemia. Among the participants, $70(61.9 \%)$ owned glucometers but only $30 / 56$ (53.6\%) had ever tested their blood glucose to confirm hypoglycaemia before managing symptoms suspected to be hypoglycaemia. Taking timely meals was the measure adopted by $72.5 \%$ of patients with hypoglycaemia to relieve the symptoms. Approximately $10.6 \%$ of participants regularly took table sugar, soft drink, glucose tablets or other forms of glucose with them while going out.

The frequency and times of hypoglycaemic symptoms occurrence among study participants are as shown in Figure 2. Most symptoms of hypoglycaemia in the Study occurred in the afternoon before lunch (28.3\%), and least occurred at night. Almost a quarter of participants (23.5\%) developed both daytime and nocturnal hypoglycaemia. Almost all spouses 108 (95.6\%) of diabetic participants know of the diabetic status of their spouses, more wives know about the diabetic status of their husbands compared with husbands knowing the diabetic status of their wives.

Most of the patients who reported hypoglycaemic symptoms, 36 (64.3\%) perceived that the main cause of hypoglycaemic symptom was missed/delayed or inadequate meal intake rather than excessive/unaccustomed exercise or overdose of anti-diabetic medications.

The incidence of hypoglycaemia subtypes in this study was mild/moderate hypoglycaemia reported by $45 / 56$ (80.4\%) and severe hypoglycaemia reported by $11 / 56(19.6 \%)$ patients. Hospital admission for hypoglycaemia symptoms was reported by $9 / 56(16.1 \%)$ patients of which $2(3.6 \%)$ had more than 2 hospital admissions (Table 2).

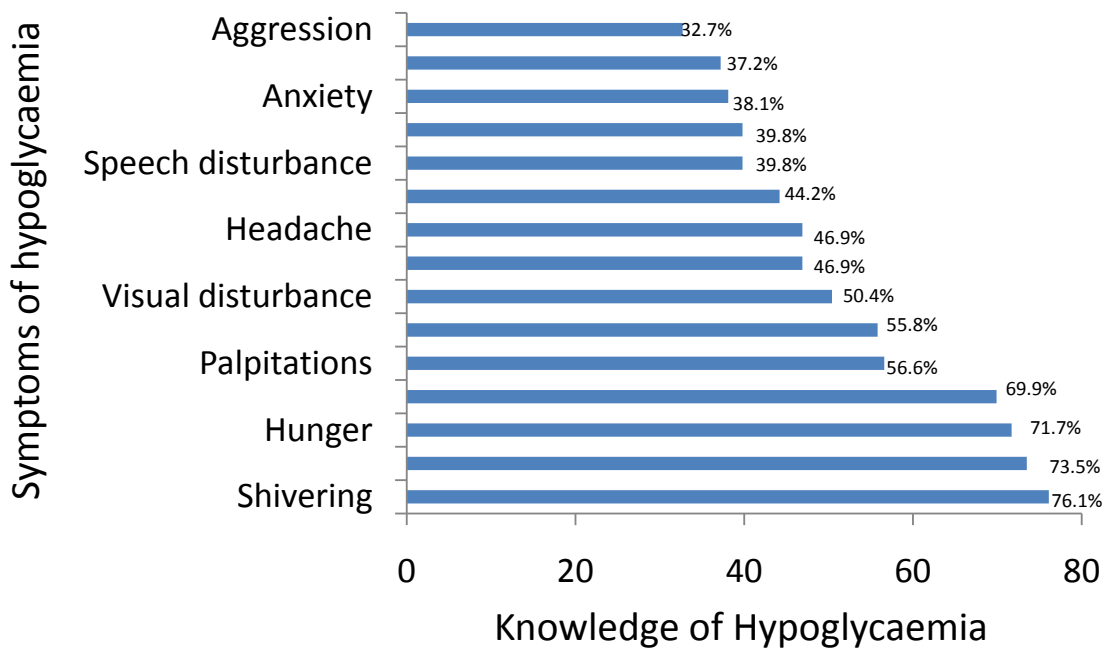

Figure 1. Prevalence of hypoglycaemic symptoms among type 2 diabetic patients. 

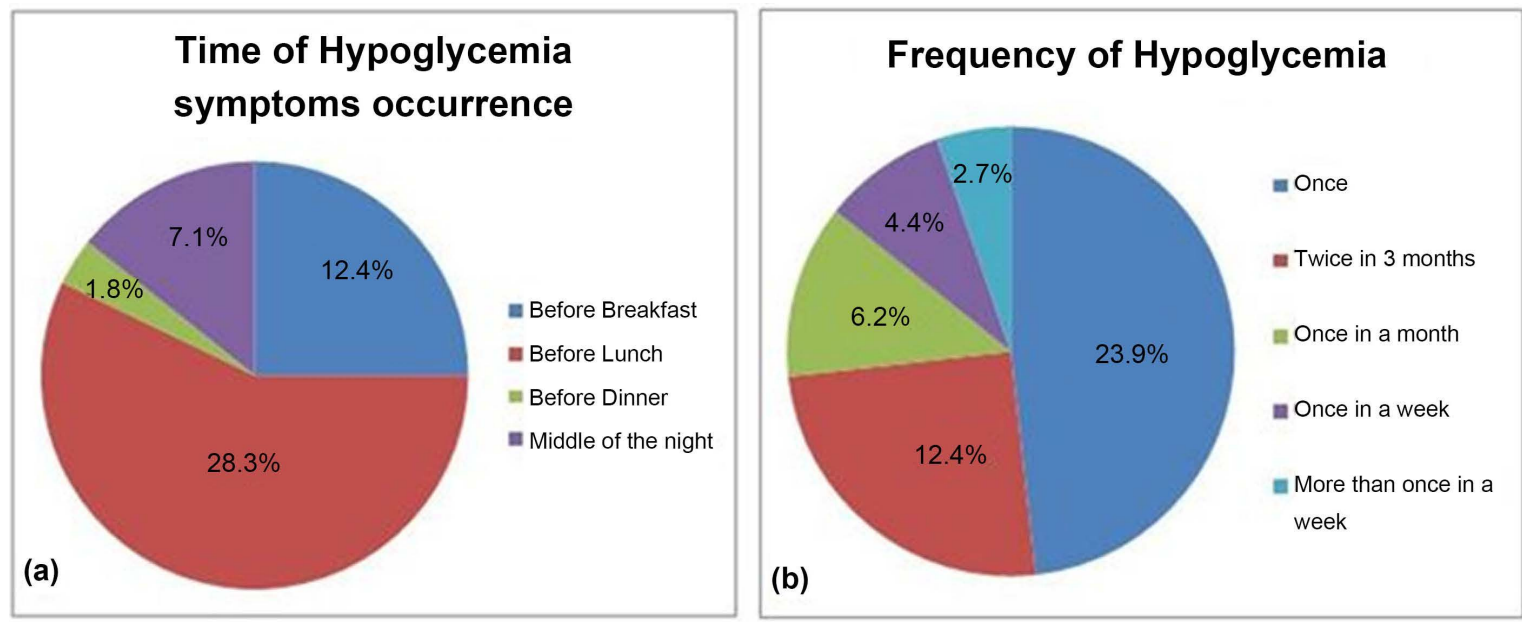

Figure 2. Time and frequency of hypoglycaemic symptoms occurrence among type 2 diabetic patients.

Table 2. Patterns of hypoglycaemia occurrence among the study participants.

\begin{tabular}{|c|c|c|c|}
\hline & \multirow{2}{*}{ Variable } & \multicolumn{2}{|c|}{$\mathrm{N}=113$} \\
\hline & & Frequency & Percentage \\
\hline \multirow{5}{*}{ Cause of hypoglycaemia } & Missed/delayed meal & 36 & 64.3 \\
\hline & Over medication or insulin regimen & 18 & 32.1 \\
\hline & Acute illness & 1 & 1.8 \\
\hline & Alcohol intake & 0 & 0.0 \\
\hline & Vigorous exercise & 1 & 1.8 \\
\hline \multirow{5}{*}{ Possession of glucometer } & $\begin{array}{l}\text { Yes, Do you use glucometer when } \\
\text { symptomatic? }\end{array}$ & 70 & 61.9 \\
\hline & Yes & 30 & 26.5 \\
\hline & No & 40 & 35.4 \\
\hline & No & 43 & 38.1 \\
\hline & Once & 30 & 26.5 \\
\hline \multirow{4}{*}{$\begin{array}{c}\text { Frequency of } \\
\text { blood sugar check }\end{array}$} & 2 - 3 times & 13 & 11.5 \\
\hline & 4 - 5 times & 39 & 34.5 \\
\hline & Everyday & 12 & 10.6 \\
\hline & Never to occasionally & 19 & 16.8 \\
\hline \multirow{6}{*}{$\begin{array}{c}\text { Does your spouse } \\
\text { know you have diabetes? }\end{array}$} & Yes, Can they recognise symptoms? & 108 & 95.6 \\
\hline & Yes, Do they know what to do? & 59 & 52.2 \\
\hline & Yes & 51 & 45.1 \\
\hline & No & 8 & 7.1 \\
\hline & No & 49 & 43.4 \\
\hline & No & 5 & 4.4 \\
\hline \multirow{2}{*}{ Regular meals } & Yes & 80 & 70.8 \\
\hline & No & 33 & 29.2 \\
\hline \multirow{3}{*}{$\begin{array}{l}\text { Do you carry cubes of sugar } \\
\text { or other forms of glucose } \\
\text { around when going out? }\end{array}$} & Yes & 12 & 10.6 \\
\hline & No & 101 & 89.4 \\
\hline & Yes, How many times? & 9 & 8.0 \\
\hline \multirow{3}{*}{$\begin{array}{l}\text { Hospital admission } \\
\text { due to hypoglycaemia }\end{array}$} & Once & 7 & 6.2 \\
\hline & $2-3$ times & 2 & 1.8 \\
\hline & No & 104 & 92.0 \\
\hline
\end{tabular}


As shown in Table 3, multivariate logistic analysis revealed that older age, longer duration of diabetes, possession of a glucometer and use of insulin were associated with higher odds of hypoglycaemia. Participants who were on insulin had 4.5 times higher odds of hypoglycaemia compared with those who were not. There was no independent association between report of hypoglycaemia symptoms by participants and fasting blood sugar and carriage of sugar around, respectively.

\section{Discussion}

This descriptive study was done to assess the incidence of occurrence of hypoglycaemia symptoms among type 2 diabetics individuals, their knowledge of hypoglycaemia and their practices with respect to managing reported hypoglycaemia.

The findings in this study suggest that there is a significant risk of hypoglycaemia in patients who are on anti-diabetic agents. The risk was particularly moderate for symptomatic hypoglycaemia (19.6\%). More than three-quarter (80.4\%) of the study participants reported one or other symptoms of hypoglycaemia. Shivering, sweatiness and hunger were the most common symptoms reported by diabetic patients.

Approximately half of diabetic patients in this study had experienced hypoglycaemic symptoms. This shows that hypoglycaemia is an important complication that should always be explored and addressed. The reported risk of hypoglycaemia in this study, $45.1 \%$ is similar to $43.3 \%$ reported by Fritsche et al. [17], and $45 \%$ reported by Donnelly et al. [18] but lower than $64 \%$ by Henderson et al. [19] and 75.3\% reported by Dhuha at al. [20]. It is encouraging to know that the majority of the patients were able to recognize hypoglycaemic symptoms, as well as understand the hypoglycaemia action plan. This suggests that the education they received on diabetes during the clinic visits is effective in covering this aspect of diabetes care. This finding is similar to that from an online survey in San Diego (2011), wherein most T2DM patients were aware of the symptoms of hypoglycaemia [21]. The finding in this study also agreed with a similar study done in India in 2013, where two-thirds of patients had good knowledge of the symptoms

Table 3. Association of occurrence of reported hypoglycaemia and sociodemographic and clinical characteristics among the study participants.

\begin{tabular}{cccc}
\hline Variable & Odds Ratio & $95 \% \mathrm{CI}$ & p-value \\
\hline Fasting blood sugar & 1.090 & $0.944-1.258$ & 0.240 \\
Age & 1.65 & $1.32-2.05$ & 0.004 \\
Duration of Diabetes & 1.66 & $1.22-2.36$ & 0.030 \\
Possession of glucometer & 1.09 & $1.09-1.72$ & 0.041 \\
Carriage of sugar around & 0.129 & $0.014-1.213$ & 0.073 \\
Insulin use & 4.50 & $3.42-5.32$ & 0.001 \\
\hline
\end{tabular}


of hypoglycaemia [12]. However, a study done in Kaduna, Nigeria, involving 347 patients attending two different outpatient clinics (117 of whom were diabetics) showed that a smaller number $(34.2 \%)$ of patients were aware of the symptoms of hypoglycaemia [22]. Missed/delayed or inadequate meals were the most common precipitating factors responsible for hypoglycaemic episodes in this study; this agreed with findings in other studies [8] [23] [24].

In this study, most participants with hypoglycaemia had "mild/moderate" hypoglycaemia; the incidence of "severe" hypoglycaemia episodes was reported by $19.6 \%$ and hypoglycaemia requiring hospital admission by $16.1 \%$ of the patients. Similar study reported incidence of $19 \%$ among Indians [25] and $20 \%$ in a survey in America where $10 \%$ of them required assistance from another party and $6 \%$ were managed at Emergency Department [26]. The finding was also higher than 3\% reported by Donnelly et al. [18] and 7\% reported by UK Hypoglycaemia study [10]. The higher incidence in this study may be due to misclassification of mild/moderate symptoms as severe which probably led to unnecessary help from relatives or presentation for treatment in the emergency room, hence could have led to overestimation of severe hypoglycaemia in this study.

On the predictors/determinants of hypoglycaemia in our study, a number of factors were identified that influenced the risk of hypoglycaemia. We found an association between FBS, carriage of sugar around, older age, longer duration of diabetes, possession of a glucometer and use of insulin, respectively, and the risk of hypoglycaemia on bivariate analysis. However, this association disappeared on regression analysis for FBS, carriage of sugar around but remained for older age, longer duration of diabetes, possession of a glucometer and use of insulin. The increased risk with insulin use (OR-4.50, 95\% CI-3.42 - 5.32) is in keeping with results of a number of observational studies such as UK Hypoglycaemia study [10], and a study by Donnelly et al. [18] which found increased incidence rates of hypoglycaemia in patients on insulin (25\%) with longer usage. Self-monitoring of blood glucose (SMBG) was also predictive of hypoglycaemia episodes, most probably because of increased awareness in cases where episodes were asymptomatic. The unpleasant symptoms and consequent hypoglycaemia may result in fear of subsequent hypoglycaemia. Fear of future hypoglycaemic events may lead to corrective or counteractive action to prevent hypoglycaemia including repeated monitoring of blood glucose at the expense of undesirably high glucose levels [27]. This repeated significant hypoglycaemia blunts hormonal responses to hypoglycaemia leading to impaired awareness of hypoglycaemia (Hypoglycaemia Associated Autonomic Failure, HAAF) [28].

The practice of SMBG as a way to detect and prevent future occurrence of hypoglycaemic episodes in this study was low as only approximately half of participants $(53.6 \%)$ has ever practiced SMBG to confirm their hypoglycaemia symptoms before managing it. It is well known that SMBG aids in better glucose control and prevention of hypoglycaemia among diabetics especially those on insulin, by allowing for adjustment in diet, physical activity and medications in response to test results [29] [30]. 
An interesting finding in this study was the fact that higher proportion of wives know of the diabetic status of their husbands compared to husbands knowing of the diabetic status of their wives. This may be related to perception of African women who sometimes believe that if their husbands know about their diabetic status it could make them marry other women as they might be considered not to be sexually appealing to them again. However, this is erroneous!

\section{Strengths of the Study}

With paucity of studies on hypoglycaemia in this environment, this study which explored knowledge of symptoms, frequency of hypoglycaemic episodes and practices adopted by patients during hypoglycaemia will serve as a reference study for future studies.

\section{Limitations}

The limitations of this study include its relatively small sample size; hence higher-powered studies are suggested to further explore the associations seen. Also, its cross-sectional nature only enables us to detect associations but not causality, hence longitudinal studies is suggested to further this study. Estimation of hypoglycaemia incidence was based on symptoms as reported by patients rather than confirmed low blood glucose levels with glucometer. However, this was not done because of low number of patients that correlated their symptoms with objective blood glucose measurements. Hence, these reported symptoms might not necessarily be symptoms of hypoglycaemia, since most of these symptoms are non-specific, that is, they are not pathognomic of hypoglycaemia.

\section{Conclusion}

The burden of hypoglycaemia in patients with type 2 diabetes is significant. Hence, the most important goal is to identify the patients at a high risk of hypoglycaemia and modify their treatment regimens based upon individual patient characteristics. Achieving adequate glycaemic control without causing troublesome hypoglycaemia is the key to providing optimum care to individuals with diabetes. Education should be provided at a level appropriate to the understanding of each patient. Educating patients for early identification of hypoglycaemic symptoms, its causes, and the various preventive measures are all important to reduce the burden of hypoglycaemia. Regular SMBG as one of the effective ways to monitor blood glucose trends and identifying asymptomatic hypoglycaemia should be encouraged.

\section{What Is Known about This Topic}

- Hypoglycaemia is a major and serious complication of diabetes management.

- Hypoglycaemia limits achieving diabetes goals in management.

- Insulin and other insulin secretagogues are major anti-diabetic agents that 
cause hypoglycaemia in diabetes patients.

\section{What This Study Adds to the Topic}

- Burden of hypoglycaemia even among type 2 diabetics is high although mainly mild to moderate in severity.

- Practice of self monitoring of blood sugar (SMBG) to confirm/detect hypoglycaemia is low, most patients depend on symptomatology to assume hypoglycaemia.

- Higher proportion of wives is aware of the diabetic status of their husbands compared to husbands knowing about the diabetic status of their wives.

\section{Acknowledgements}

The authors wish to thank Stephen Asaolu for assisting with data analysis.

\section{Ethical Approval}

Ethical approval was obtained from the Ethics Committee of LAUTECH Teaching Hospital, Ogbomoso.

\section{Funding}

The authors disclosed no receipt of financial support for the research and/or publication of this article.

\section{Authors' Contributions}

MAO conceptualized; designed, involved in data collection, analysis interpretation of analysis and drafting of the manuscript; AAO, ACE and ATA were all involved in the initial drafting of the manuscript. All authors critically reviewed, edited and approved the manuscript.

\section{Conflicts of Interest}

The authors declare no competing interest.

\section{References}

[1] American Diabetes Association (2013) Standards of Medical Care in Diabetes-2013. Diabetes Care, 36, S11-S66. https://doi.org/10.2337/dc13-S011

[2] Nyenwe, E.A., Jerkins, T.W., Umpierrez, G.E. and Kitabchi, A.E. (2011) Management of Type 2 Diabetes: Evolving Strategies for the Treatment of Patients with Type 2 Diabetes. Metabololism, 60, 1-23. https://doi.org/10.1016/j.metabol.2010.09.010

[3] Kalra, S., Mukherjee, J.J., Venkataraman, S., Bantwal, G., Shaikh, S. and Saboo, B. (2013) Hypoglycemia: The Neglected Complication. Indian Journal of Endocrinology and Metabolism, 17, 819-834. https://doi.org/10.4103/2230-8210.117219

[4] Brackenridge, A., Wallbank, H., Lawrenson, R.A. and Russell-Jones, D. (2006) Emergency Management of Diabetes and Hypoglycaemia. Emergency Medicine Journal, 23, 183-185. https://doi.org/10.1136/emj.2005.026252 
[5] Gehlaut, R.R., Dogbey, G.Y., Schwartz, F.L., Marling, C.R. and Shubrook, J.H. (2015) Hypoglycemia in Type 2 Diabetes-More Common than You Think: A Continuous Glucose Monitoring Study. Journal of Diabetes Science and Technology, 9 , 999-1005. https://doi.org/10.1177/1932296815581052

[6] Nathan, D.M. (2014) The Diabetes Control and Complications Trial/Epidemiology of Diabetes Interventions and Complications Study at 30 Years: Overview. Diabetes Care, 37, 9-16. https://doi.org/10.2337/dc13-2112

[7] King, P., Peacock, I. and Donnelly, R. (1999) The UK Prospective Diabetes Study (UKPDS): Clinical and Therapeutic Implications for Type 2 Diabetes. British Journal of Clinical Pharmacology, 48, 643-648.

https://doi.org/10.1046/j.1365-2125.1999.00092.x

[8] Cryer, P.E. (2008) The Barrier of Hypoglycemia in Diabetes. Diabetes, 57, 3169-3176. https://doi.org/10.2337/db08-1084

[9] Cryer, P.E., Davis, S.N. and Shamoon, H. (2003) Hypoglycemia in Diabetes. Diabetes Care, 26, 1902-1912. https://doi.org/10.2337/diacare.26.6.1902

[10] UK Hypoglycaemia Study Group (2007) Risk of Hypoglycaemia in Types 1 and 2 Diabetes: Effects of Treatment Modalities and Their Duration. Diabetologia, 50, 1140-1147. https://doi.org/10.1007/s00125-007-0599-y

[11] Shafiee, G., Mohajeri-Tehrani, M., Pajouhi, M. and Larijani, B. (2012) The Importance of Hypoglycemia in Diabetic Patients. Journal of Diabetes \& Metabolic Disorders, 11, 17. https://doi.org/10.1186/2251-6581-11-17

[12] Shriraam, V., Mahadevan, S., Anitharani, M., Jagadeesh, N.S., Kurup, S.B. and Vidya, T.A. (2015) Knowledge of Hypoglycemia and Its Associated Factors among Type 2 Diabetes Mellitus Patients in a Tertiary Care Hospital in South India. Indian Journal of Endocrinology and Metabolism, 19, 378-382. https://doi.org/10.4103/2230-8210.152779

[13] Patel, A., MacMahon, S., Chalmers, J., Neal, B., Billot, L. and Woodward, M. (2008) Intensive Blood Glucose Control and Vascular Outcomes in Patients with Type 2 Diabetes. The New England Journal of Medicine, 12, 2560-2572. https://doi.org/10.1056/NEJMoa0802987

[14] Duckworth, W., Abraira, C., Moritz, T., Reda, D., Emanuele, N. and Reaven, P.D. (2009) Glucose Control and Vascular Complications in Veterans with Type 2 Diabetes. The New England Journal of Medicine, 360, 129-139. https://doi.org/10.1056/NEJMoa0808431

[15] American Diabetes Association (2014) Standards of Medical Care in Diabetes-2014. Diabetes Care, 37, S14-S80. https://doi.org/10.2337/dc14-S014

[16] Chaudhury, A., Duvoor, C., Reddy-Dendi, V.S., Kraleti, S., Chada, A. and Ravilla, R. (2017) Clinical Review of Antidiabetic Drugs: Implications for Type 2 Diabetes Mellitus Management. Frontiers in Endocrinology, 8, 6.

https://doi.org/10.3389/fendo.2017.00006

[17] Fritsche, A., Halin, A., Landgraf, W. and Haring, H.I. (2013) Incidence of Hypoglycaemia in Patients with Type 2 Diabetes: A Subgroup Analysis from the GINGER Study. European Endocrinology, 9, 1-3. https://doi.org/10.17925/EE.2013.09.01.1

[18] Donnelly, L.A., Morris, A.D., Frier, B.M., Ellis, J.D., Donnan, P.T. and Durrant, R.L. (2005) Frequency and Predictors of Hypoglycaemia in Type 1 and Insulin-Treated Type 2 Diabetes; a Population-Based Study. Diabetes Medication, 22, 749-755. https://doi.org/10.1111/j.1464-5491.2005.01501.x

[19] Henderson, J.N., Allen, K.V., Deary, I.J. and Frier, B.M. (2003) Hypoglycaemia in Insulin Treated Type 2 Diabetes: Frequency Symptoms and Impaired Awareness. 
Diabetes Medication, 20, 1016-1021.

https://doi.org/10.1046/j.1464-5491.2003.01072.x

[20] Dhuha, T.N., Omran, S.H. and Abass, A.M. (2016) Predictors of Hypoglycaemia in Insulin-Treated Patients with Type 2 Diabetes Mellitus in Basrah. World Journal of Diabetes, 7, 470-480. https://doi.org/10.4239/wjd.v7.i18.470

[21] Healio, Endocrine Today. Survey: People with Diabetes Uncertain about Management of Hypoglycemia. http://www.healio.com/endocrinology/diabetes

[22] Hamoudi, N.M., Al Ayoubi, I.D., Vanama, J., Yahaya, H. and Usman, U.F. (2012) Assessment of Knowledge and Awareness of Diabetic and Non-Diabetic Population towards Diabetes Mellitus in Kaduna, Nigeria. Journal of Advanced Scientific Research, 3, 46-50. https://doi.org/10.7324/JAPS.2012.2410

[23] Briscoe, V.J. and Daris, S.N. (2006) Hypoglycaemia in Type 1 and Type 2 Diabetes: Physiology, Pathophysiology and Management. Clinical Diabetes, 24, 115-121. https://doi.org/10.2337/diaclin.24.3.115

[24] Fowler, M.J. (2008) Hypoglycaemia. Clinical Diabetes, 26, 170-173. https://doi.org/10.2337/diaclin.26.4.170

[25] Shriram, V., Mahadevan, S., Anitharani, M., Jagadeesh, N.S., Kurup, S.B. and Vidya, T.A. (2017) Reported Hypoglycaemia in Type 2 Diabetes Mellitus Patients: Prevalence and Practices-a Hospital-Based Study. The Indian Journal of Endocrinology and Metabolism, 21, 148-153. https://doi.org/10.4103/2230-8210.196002

[26] Endocrine Today (2011) Survey Reveals Low Hypoglycaemia Awareness among Patients with Diabetes. American Association of Clinical Endocrinologists 20th Annual Meeting.

[27] Cox, D.J., Irvine, A., Gonder-Frederick, L., Nowacek, G. and Butterfield, J. (1987) Fear of Hypoglycemia: Quantification, Validation, and Utilization. Diabetes Care, 10, 617-621. https://doi.org/10.2337/diacare.10.5.617

[28] Segel, S.A., Paramore, D.S. and Cryer, P.E. (2002) Hypoglycaemia-Associated Autonomic Failure (HAAF) in Advanced Type 2 Diabetes. Diabetes, 51, 724-733. https://doi.org/10.2337/diabetes.51.3.724

[29] Benjamin, E.M. (2003) Self-Monitoring of Blood Glucose. The Basics. Clinical Diabetes, 20, 45-47. https://doi.org/10.2337/diaclin.20.1.45

[30] Garg, S. and Hirsch, I.B. (2010) Self-Monitoring of Blood Glucose. International Journal of Clinical Practice, 166, 1-10. https://doi.org/10.1111/j.1742-1241.2009.02271.x 